\title{
Dual epidemics of deaths by heroin overdose and suicide
}

\author{
Alen J Salerian* \\ Salerian Centre for Neuroscience and Pain, USA
}

\begin{abstract}
Introduction: Dual epidemics of deaths by heroin overdose and suicide were recorded in US from 2000 to 2014.

Also from 2000 to 2014 an estimated 11.342 physicians -accused of overprescribing opiates and treating some estimated 8 million people with chronic pain, addiction or psychiatric disorders-were forced out of medical practice.

The aim of this study is to determine whether there is a correlation between the dual epidemics and possible adverse influences mediating access to opiate treatment.

Method: We have reviewed CDC vital statistics from 2000 to 2014. We also studied diverse influences on populations with increased risk of heroin addiction and suicide from 2000 to 2014 .

Results: From 2000 to 2014 the US heroin deaths rate jumped from 0.7 to 3,4 and deaths by suicide from 10.1 to 13 per 100.000 population. There was a statistically strong correlation $(\mathrm{r}=0.9)$ between the suicides and heroin deaths.

From 2000 to 2014 the accidental overdose deaths rose from 3 to 14 per 100.000 population. The percentage of deaths associated with prescription opiates declined from $38,1 \%$ to $28 \%$ while the percentage of heroin deaths jumped from $11 \%$ to $28 \%$.

From 2000 to 2014 some estimated 11.342 accused of over prescribing opiates were forced out of practice with some estimated 6.8 million opiate dependent patients enduring disruption and or discontinuation of stable treatment.

Discussion: Reduction of access to prescription opiates by disrupting stable treatment of a population vulnerable to mood instability might have been an independent contributor to the dual epidemics of heroin overdose deaths and suicides from 2000 to 2014 .
\end{abstract}

\section{Introduction}

US has been experiencing dual epidemics of deaths by heroin overdose and suicides from 2000 to 2014 (Table 1) [1].

Studies suggest significantly heightened suicidal deaths in depression [2-4], bipolar disorder [5,6], schizophrenia [7,8] substance use disorder $[8,9]$, alcohol use disorder $[10,11]$ and chronic pain $[12,13]$.

Heroin addiction is a chronic relapsing disease with symptoms of compulsive drug seeking and use, tolerance and dependence. A complex genetic susceptibility to heroin addiction has been estimated to be 40 to $60 \%[14,15]$.

Several studies suggest a high co morbidity of depression or depressive symptomatology [16-18] bipolar disorder [17,19] and heroin addiction.

Endorphins mediate mood, pain and addiction and opiates represent essential psychopharmacological agents for chronic pain,

Table 1. 2009-2014 - US Deaths from Suicide and Heroine Per 100.000 Population.r=0.9. Source: CDC vital statistics.

\begin{tabular}{|c|c|c|}
\hline Year & Heroine & Suicide \\
\hline 2000 & 0.7 & 10.5 \\
\hline 2005 & 0.7 & 11 \\
\hline 2008 & 0.9 & 11.6 \\
\hline 2010 & 1.0 & 12.1 \\
\hline 2011 & 1.3 & 12.3 \\
\hline 2014 & 3.4 & 13.0 \\
\hline
\end{tabular}

addiction (methadone, heroin and buprenorphine) [20] and treatment refractory depression $[21,22]$.

Opiates seem to have neuro protective properties against premature death for a large population with chronic pain, psychiatric disorders and addiction. This observation is consistent with studies of a strikingly high mortality associated with discontinuation of opiates (Table 2)

Table 2. Criminalization of Psychiatry and Pain Medicine.

\section{Possible Mechanism of Adverse Action.}

Deaths by suicide increased from 10.1 to 12.9

$\uparrow \uparrow \uparrow$

Deaths by heroine overdose increased from 0.4 to 3

$\uparrow \uparrow \uparrow$

Deaths by overdose increased from 3 to 14.7 .

$\downarrow \downarrow \downarrow$

$\%$ of deaths by prescription opiates relative to total overdose deaths declined from $46 \%$ to $38 \%$.

$\downarrow \downarrow \downarrow$

The rate of increase of deaths from prescription opiates( 4 times) was less relative to the rate of increase of total overdose deaths ( 4.9 times).

Correspondence to: Alen J Salerian, Salerian Centre for Neuroscience and Pain, 5325 Westbard Avenue, 08 Bethesda Maryland 20816, USA, Tel: 3012049004; E-mail: alensalerian@Gmail.com

Key words: suicide, suicide epidemic, opiates, heroin overdose, substance use disorders

Received: May 10, 2017; Accepted: May 31, 2017; Published: June 02, 2017 
[16,17,23-25] and also with a crucial postmortem study indicating severe depletion of brain endorphins in patients with depression and successful suicide [26].

Kakko and colleagues [26] reported a $20 \%$ mortality rate among heroin addicts one year after discontinuing opiate treatment. Based upon 5 independent studies one year mortality rate of a large population with chronic pain and psychiatric disorders seems to be $16 \%$ without opiate treatment.

From 2000 to 2014, some estimated 11.342 physicians accused of overprescribing opiates were forced out of practice. Consequently, some estimated 8 million patients with chronic pain, addiction and treatment refractory depression endured disruption or discontinuation of stable opiate treatment (Table 3 ).

The aim of this study is to determine whether reduction of access to prescription opiates has been an independent contributory influence in the epidemics of deaths by heroin overdose and suicide from 2000 to 2014 .

\section{Method}

We have reviewed CDC vital statistics from 2000 to 2014. We also studied adverse influences on patient populations with heightened risk of suicide by search engines Google scholar, Cochran library and Medline. We use the keywords, criminalization of psychiatry, prescription opiates, opiate withdrawal, suicide in psychiatric disorders, bipolar disorder and suicide, suicide in depression, schizophrenia and suicide, PTSD and suicide.

\section{Results}

From 2000 to 2014 suicidal deaths increased from 10.1 to 13 per 100.000 population, heroin overdose deaths jumped from 0.7 to 3.5 per hundred thousand population.

From 2000 to 2014 the accidental overdose deaths rose, the percentage of deaths associated with prescription opiates declined from $38,1 \%$ to $28 \%$ while the percentage of heroin deaths jumped from $11 \%$ to $28 \%$. Heroin deaths rose from 0.7 per 100.000 population in 2000 to 3.4 per 100.000 population in 2014 . There was a statistically strong correlation $(r=0.9)$ between the suicides and heroin deaths (Tables 1 and 4). From 2000 to 2014 some estimated 11.340 criminally prosecuted physicians for over prescribing opiates were forced out of practice with some estimated 8 million opiate dependent patients enduring disruption and or discontinuation of stable treatment.

\section{Discussion}

From 2000 to 2014, the US deaths by suicide and heroin overdoseconsistent with stable economic conditions, psychiatric advances and public education on suicide and declining crime and deaths by homicide- were expected to decline but they did not. The above findings are consistent with a unique " $x$ " influence counteracting inhibitory influences upon deaths by suicide and heroin.

The statistically significant correlation $(r=0.9)$ between the annual suicide rates and the annual death rates from heroin overdose is consistent with both epidemics sharing a sensitive dependence on prescription opiates which are essential therapeutic agents for heroin addiction, pain and psychiatric disorders. Prescription opiates also reduce mortality associated with heroin addiction pain and psychiatric disorders (Figure 1).

All of the above collectively indicate that reduction of prescription opiates for a large population dependent on prescription opiates and vulnerable to mood instability, might have been an independent crucial "X" factor in the US epidemics of suicide and heroin deaths (Table 5 and 6).

Also, noteworthy are, deaths by accidental overdoses increased by 400 percent yet the percentage of prescription opiate overdose fatalities decreased from $46 \%$ in 2000 to $38 \%$ in 2014 . This finding suggests, the man-made barriers have had some impact and have decreased overdose deaths from prescription opiates.

Furthermore, crime in general including violent crimes and homicides also declined in contrast to the rising deaths from suicide and illicit drugs. This observation further supports a positive correlation between criminalization of medicine, reduction of access to prescription opiates and the selective rise in use of illicit opiates and deaths by heroin overdose and suicide.

\section{Limitations of this study include the following}

A. Recording and registration errors might have contaminated vital statistics.

B. Lack of precise mortality and suicide data associated with practice closures.

C. Lack of precise data about the number of patients with discontinued or disrupted treatment.

At present, we do not know why the adverse effects of criminalization of medicine did not begin to emerge until 2000, some 25 years after the US Congress authorized new legislation about prescription opiates. It is possible that this is consistent with a delayed butterfly effect of initial errors observed in complex systems [40]. It is also possible that yet unknown environmental factors might have also contributed to the suicide epidemic.

Despite its limitations, this study offers evidence to suggest that disruption of opiate treatment might have- independent of any another possible influence- contributed to the current dual epidemics [41-46].

Our observations demand further scientific scrutiny and validation. Further studies to investigate independent and possibly yet unknown or unidentified influences in suicide are necessary [47-52].

Table 3. A Causal Association Between the US Suicide Epidemic and the Criminalization of Psychiatry and Pain Medicine.

\section{Independent Observations}

1 The US suicide epidemic ( 42,000 or 13 deaths per 100.000 population) has been worsening at a time when the suicide rates in Japan and Western Europe have been declining. Unlike Japan and Western Europe the US has been criminalizing psychiatry and pain medicine since mid-80s.

2 Multiple studies have established a link between discontinuation of opiates with strikingly high suicide rates in stable patient populations. The criminalization of psychiatry and pain medicine have prompted a significant number of practice closures and a large number of opiate dependent patients without adequate care.

3 Approximately $1 / 3$ of the US population suffer from chronic pain, addiction and psychiatric problems associated with vulnerability to depression and suicide. Since antiquity the therapeutic benefits of opiates have been known. The criminalization of psychiatry and pain medicine seriously limited access to opiates and have created a hostile environment for millions of Americans with disabilities at a time of major epidemics of mental illness and chronic pain.

4 High unemployment and adverse economic conditions-often contributory to the worsening of suicide rates - have had no impact on the US suicide epidemic. 


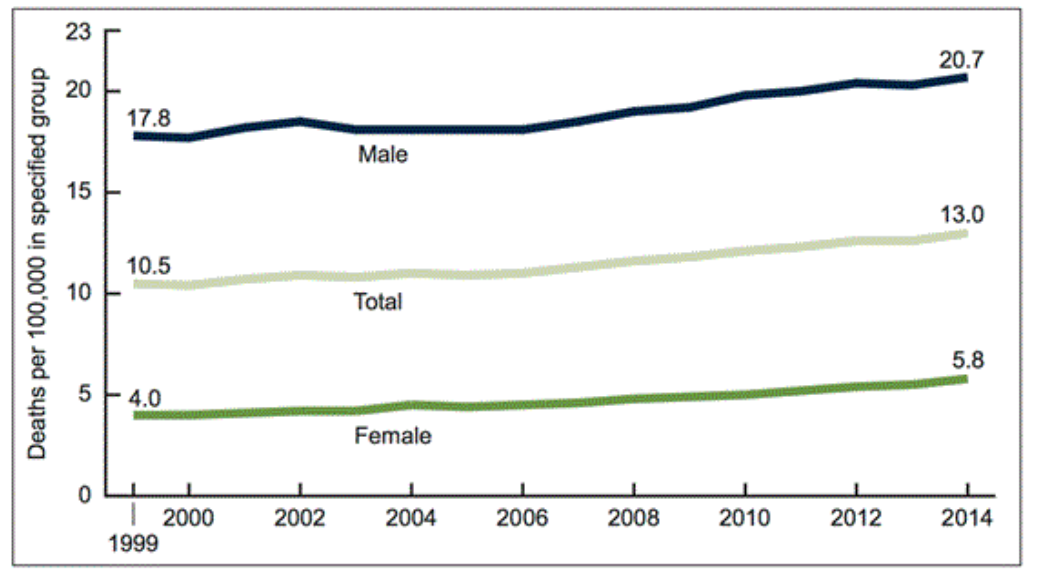

Figure 1. Age-adjusted suicide rates, by sex: United states, 1999-2014.Note. Suicides are identified with codes UO3, X60-X84, and Y87.0 from the international statistical classification of diseases and related health problems.

Table 4. Pain Physicians From 2000 To 2014*."DEA does not provide specific data of the annual and total number of physicians investigated or prosecuted. The above numbers are the best educated estimates based upon available information from diverse sources [27-29].

\begin{tabular}{|l|l|}
\hline Pain Physicians From 2000 To 2014. \\
\hline 1 & \# People in need of pain treatment: 110 million. \\
\hline 2 & \# Physicians under investigation every year: 600. \\
\hline 3 & $\begin{array}{l}\text { \% Pain physicians under investigation }: 12 \% 2000-2014 \\
\text { \# Pain physicians delicensed: } 9000 .\end{array}$ \\
\hline
\end{tabular}

Table 5. Criminalization of Psychiatry and Pain Medicine.

Criminalization of Psychiatry and Pain Medicine

$1 \quad$ The comprehensive forfeiture act of 1984: law enforcement agencies can seize physician's assets without any hearing or trial

2 The drug abuse prevention and control act of 1970: a physician may be prosecuted for failing to follow standard medical practice in prescribing controlled substances

Table 6. Endorphin (opiates) - Suicide Connection: Neurobiology.

Endorphin (opiates) - Suicide Connection: Neurobiology.

1 Brains of suicide victims are endorphin depleted [30].

2 Endorphins are crucial for pain and mood regulation. Any adverse influence may contribute to diminished resilience against depression and suicide [31-33].

$320 \%$ death rate in one year among heroin addicts who discontinued buprenorphine [34].

$4 \quad$ Alarmingly high suicide rates among patients with discontinued opiate treatment following practice closures [35-37].

5 MRI evidence of brain atrophy with chronic pain [38,39]

\section{Conclusion}

Criminalization of medicine associated reduction of access to prescription opiates or disrupting stable treatment of a vulnerable and opiate dependent population might have been an independent contributor to the epidemics of deaths by suicide and heroin overdose from 2000 to 2014 .

Our findings may have serious implications for suicide prevention, treatment of addictive disorders and public policy. Healthcare professionals and policymakers must be warned of heightened risk of mortality and morbidity associated with disruption of stable opiate treatment.

\section{Significance statement}

Reduced access to prescription opiates-independent of any other factors -might have contributed to the epidemics of deaths by suicide and heroin overdose.
Without opiate treatment, a large population with pain and psychiatric disorders are at risk for premature death. Extreme caution must be exercised prior to discontinuing opiates of stable patients.

\section{Conflict of interest statement}

This is to confirm that I have no conflict of interest in the publication of this manuscript. I also confirm that I have not received any monies for the preparation of this manuscript.

\section{References}

1. Centers for Disease Control and Prevention (CDC) Web-based Injury Statistics Query and Reporting System (WISQARS) [Online]. (2014) National Center for Injury Prevention and Control, CDC (producer)

2. Black DW, Barrack G, Winokur G (1985) Excess Mortality Among Psychiatric Patients. The Iowa Record-Linkage Study. JAMA 253: 58-61.[Crossref]

3. Blair-West, GW, Cantor CH, Mellsop GW, Eyeson-Annan ML (1999) Lifetime suicide risk in major depression: sex and age determinants. J Affect Disord 55: 171-178. [Crossref]

4. Miles CP (1977) Conditions predisposing to suicide: A review. J Nerv Ment Dis 164 [Crossref]

5. Jamison KR (2000) Suicide and bipolar disorder. J Clin Psychiatry 61 Suppl 9: 47-51. [Crossref]

6. Pompili M, Innamorati M, Raja M, Falcone I, Ducci G, et al. (2008) Suicide risk in depression and bipolar disorder: Do impulsiveness-aggressiveness and pharmacotherapy predict suicidal intent? Neuropsychiatr Dis Treat 4: 247-255. [Crossref]

7. Hor H, Taylor M (2010) Suicide and schizophrenia: a systematic review of rates and risk factors.J Psychopharmacol 24: 81-89.

8. Zilber N, Schufman N, Lerner Y (1989) Mortality among psychiatric patients--the groups at risk. Acta Psychiatr Scand 79:248-56. [Crossref]

9. Darke S, Ross J (2002) Suicide risk and Among heroin user's rates risk factors. Addiction 97: 1383-1394.[Crossref]

10. Frances RJ, Franklin J, Flavin DK (1987) Suicide and Alcoholism Annals of the New York Academy of Sciences 487.

11. Rossow I, Amundsen A (1995) Alcohol abuse and suicide: a 40-year prospective study of Norwegian conscripts. Addiction 90: 685-691. [Crossref]

12. Fishbain DA (1999) The association of chronic pain and suicide. Semin Clin Neuropsychiatry 4: 221-227.[Crossref]

13. Fishbain DA, Lewis JE, Gao J (2015) The Pain-Suffering Association, A Review. Pain Medicine 16: 1057-1072. [Crossref]

14. Bart G, Heilig M, La Forge KS, Pollak I, Leal SM, et al. (2004) Substantial attributable risk related to a functional mu- opioid receptor gene polymorphism in association with heroin addiction in central Sweden. Mol Psychiatry 9: 547-549. [Crossref] 
15. Tsuang MT, Lyons MJ, Eisen SA, Goldberg J, True W, et al. (1996) Genetic influences on DSM-III R drug abuse. Am J Med Genet 67: 437-477.

16. Maremmani I, Pacini P, Pani P, Perugi G, Deltito J, et al.(2007) The mental status of 1090 heroin addicts at entry into treatment: should depression be considered a 'dual diagnosis'? Annals of General Psychiatry 6: 31.

17. Maremmani I, Maremmani AG, Rugani F, Rovai L, Pacini M, et al.(2012) Clinical presentations of substance abuse in bipolar heroin addicts at time of treatment entry. Ann Gen Psychiatry 11: 23. [Crossref]

18. Havard A, Teesson M, Darke S, Ross J (2006) Depression among heroin users: 12-Month outcomes from the Australian Treatment Outcome Study (ATOS) J Subst Abuse Treat 30: 355-362.[Crossref]

19. Tondo L, Baldessarini RJ, Hennen J, Minnai GP, Salis P, et al.(1999) Suicide attempts in major affective disorder patients with co- morbid substance use disorders. $J$ Clin Psychiatry 60(suppl 2): 63-69. [Crossref]

20. Meyer JS, Quenzer LF (2005) Psychopharmacology, Sinauer Associates.

21. Bodkin A, Zornberg G, Lucas S, Cole J (1995) Buprenorphin treatment of treatment refractory depression. J Clin Psychopharmacol 5: 49-57.[Crossref]

22. Stoll AL, Rueter S (1999) Treatment augmentation with opiates in severe and refractory major depression. Am J Psychiatry 156: 2017. [Crossref]

23. Kakko J, Svanborg KD, Kreek MJ, Heilig M (2003) One-year retention and socia function after buprenorphine assisted relapse prevention treatment for heroin dependence in Sweden: a randomized, placebo-controlled trial. Lancet 261: 662-668. [Crossref]

24. Salerian AJ (2015) Discontinuation of Opiate Treatment: A Retrospective Review Of 49 Patients. J Psychol Clin Psychiatry 2.

25. Salerian AJ (2015) Case studies of 17 patients. Journal of Case Reports and Studies 3: $1-3$.

26. Gross-Isseroff R, Dillon KA, Israeli M, Biegon A (1990) Regional lease selected increases in opioid receptor density in the brains of suicidal victims. Brain Res 530: 312-316. [Crossref]

27. Institute of medicine report, June 2012.

28. Libby RT (2005) Treating Doctors as Drug Dealers: The DEA's War on Prescription Painkillers. CATO Institute Policy no. 545.

29. Libby RT (2002) The criminalization of medicine-America's war on doctors. Docslide.

30. Isseroff RG, Dillon KA, Israeli M, Biegon A (1990) Regionally selective increases in mu opioid receptor density in the brains of suicide victims. Brain Res 530: 312-316.

31. Grant BF, Stinson FS, Dawson DA, Chou P (2004) Prevalence co-occurrence of substance use disorders and independent mood and anxiety disorders. Results from the National and Epidemiologic Survey on alcohol and related conditions. Archive Gen psychiatry 61: 807-816.

32. Salerian AJ (2015) Opiates may have neuroprotective properties against degeneration and premature death. Journal of Psychology and Clinical Psychiatry 4: 1-2.

33. Salerian AJ (2015) Endorphin agonists for treatment refractory depression, Journal of psychology and clinical psychiatry.

34. Kakko J, Svanborg DK, Kreek MI, Hellig M (2003) One-year retention and social function after buprenorphine assisted relapse prevention treatment for heroin dependence in Sweden: a randomized, placebo-controlled trial. Lancet 261: 662-668.

35. Salerian AJ (2015) Case studies of 17 patients. Journal of Case Reports and Studies 2: 5.

36. Salerian AJ (2015) Discontinuation of Opiate Treatment: A Retrospective Of 49 Patients. Journal of psychology and clinical psychiatry 2: 4.

37. Salerian AJ (2016) Injury and deaths upon practice closure: a review of four Washington DC physicians. Journal of Psychology and Ciinical Psychiatry.

38. Apkarian AV, Sosa Y, Sonty S, LEVY RM, Harden RN, et al. (2004) Chronic pain is associated with decreased prefrontal and thalamic gray matter density. The Journal of neuroscience 24: 10410-10415.

39. Baliki MN, Geha P, Apkarian AV, Chiavo D (2008) Beyond feeling: chronic pain hurts the brain disrupting the default mode network dynamics. The Journal of neuroscience 28: 1398-1403.

40. Mitchell M (2012) Complexity. Academic, Oxford University Press.

41. Bertschy G (1995) Methadone maintenance treatment: an update. European Archives of Psychiatry And Clinical Neuroscience 245: 114-124.

42. Fowler RC, Rich CL, Young D (1986) San DiegoSuicide StudyII. Substance Abuse in Young Cases. Arch Gen Psychiatry 43: 962-965.[Crossref]

43. Kendler KS, Karkowski L, Prescott CA(1999) Hallucinogen opiate sedative stimulan use and abuse in a population based female twin study. Acta Psychiatr Scand 99: 368 - 376. [Crossref]

44. Miles CP (1977) Conditions predisposing to suicide: A review. J Nerv Ment Dis 164 4. [Crossref]

45. Nyhuis PW, Gastpar M, Scherbaum N (2008)Opiate treatment in depression refractory to antidepressants and electroconvulsive therapy. J Clin Psychopharmacology 28: 593595

46. Prevalence of Mental Disorders in Europe (2014) Source: Global Health Estimates 2014 Summary Tables: DALY by cause, age and sex, by WHO Region, 2000-2012.

47. Robinson J, Hartling L, Vandermeer B, Klassen TP (2015) Intravenous immunoglobulin for presumed viral myocarditis in children and adults. Cochrane Database Syst Rev: CD004370.[Crossref]

48. Shaffer D, Gould MS, Fisher P, Trautman P, Moreau D, et al. (1996)Psychiatric Diagnosis in Child and Adolescent Suicide. Arch Gen Psychiatry 53: 339-348. [Crossref]

49. Simon NM, Zalta AK, Otto MW, Ostacher MJ, Fischmann D, et al. (2007) The association of comorbid anxiety disorders with suicide attempts and suicidal ideation in outpatients with bipolar disorder. J Psychiatr Res 41: 255-264. [Crossref]

50. Results from the 2013 National Survey on Drug Use and Health: Mental Health Findings (2014)U.S. Department of Health and Human Services, Substance Abuse and Mental Health Services Administration.

51. Woody GE, Kane V, Lewis K, Thompson R (2007) Premature deaths after discontinuation from methadone maintenance: a report. $J$ Addict Med 1:180-185. [Crossref]

52. Zarvis A, Woody G (1998) One year mortality rate for methadone treatment discharges Drug Alcohol Depend 52 (3): 257-260. [Crossref]

Copyright: (C2017 Salerian AJ. This is an open-access article distributed under the terms of the Creative Commons Attribution License, which permits unrestricted use, distribution, and reproduction in any medium, provided the original author and source are credited. 